\title{
Disease Management: Panacea, Another False Hope, or Something in Between?
}

Jobn P. Geyman, MD

Department of Family Medicine, University of Washington, Seattle, Wash

\begin{abstract}
Disease management is being promulgated by many policy makers, legislators, and a burgeoning new disease management industry as the next major hope, together with information technology and consumer-directed health care, to bring cost containment to runaway costs of health care. Many expect quality improvement as well. The concept is being aggressively marketed to employers, health plans, and government in the wake of managed care's failure to contain costs. There is widespread confusion, however, about what disease management is and what impact it will have on patients, physicians, and the health care system itself. In this article I give a current snapshot of disease management by briefly addressing (1) its rationale and growth, (2) its track record concerning costs and quality of care, and (3) its impacts on primary care.
\end{abstract}

Ann Fam Med 2007;5:257-260. DOI: 10.1370/afm.649.

\section{RATIONALE AND GROWTH OF DISEASE MANAGEMENT}

I

$\mathrm{t}$ is currently estimated that about 125 million Americans have 1 or more chronic diseases, one half of whom have 2 or more chronic ill-

nesses. Although chronic conditions cut across all age-groups, they are most common among the elderly. ${ }^{1}$ The care of chronic illness accounts for almost $75 \%$ of total health care expenditures each year. ${ }^{2}$ Just 5 chronic diseases-hypertension, heart disease, diabetes, asthma, and mood disorders-account for almost one half of US health care spending. ${ }^{3}$ As our population ages and the prevalence and costs of chronic disease increase, it is becoming increasingly clear that our current health care system, oriented as it is to acute care, is ill-suited to the optimal care of chronic conditions, where care instead of cure is the major goal.

The management of disease has long been a central goal of medicine. The term disease management, however, is a new buzzword, confusing to many, that has arisen in response to the economic and societal burden incurred by the care of chronic illness and the need to improve the quality of care for the growing populations of patients who have chronic disease. ${ }^{4}$ An additional driver of disease management, especially during the last 15 years, has been aggressive marketing by a growing commercial disease management industry seeking profits in a new market. The pharmaceutical industry, especially pharmacy benefit management companies (PBMs), has spearheaded this development since the early 1990s.

There are two basic types of disease management programs-those based on primary care and integrated within a managed care organization (eg, Group Health Cooperative and Kaiser Permanente), and commercial vendors to which employers and health plans may outsource their disease management functions. The former has been well accepted within the medical community as an important advance in the care of chronic disease. Group Health Cooperative and Kaiser Permanente have pioneered new 
approaches to chronic disease management based upon a new paradigm, the Chronic Care Model. ${ }^{5}$ For example, primary care teams are provided support in the form of electronic diabetes registries, evidence-based guidelines, patient self-management support, and decentralized on-site consultation with a diabetes expert team (a physician and a nurse specialist). ${ }^{6}$

Commercial disease management programs are quite different. As carved-out programs, they are not integrated with primary care, are for-profit ventures, and are marketed to employers and health plans primarily as a cost-containment strategy. With sophisticated information systems, disease management companies focus on patient education and more-effective patient self-management, especially by use of telephone calls, mailings, and the Internet. ${ }^{7}$ Commercial disease management programs often provide minimal communication with primary care physicians, and reception of these programs by physicians is frequently antagonistic. Physicians may at times receive telephone calls from several nurses in distant call centers about the same patient with multiple chronic conditions.

Early commercial disease management programs were designed to identify high-risk patients with a single disease and then to sell a program of patient education and self-management to employers and managed care organizations. Although these programs were marketed as strategies to contain costs and improve the quality of care of patients with chronic diseases (such as diabetes or asthma), pharmaceutical manufacturers could expect to gain increased profits in several ways. Disease management programs could support their own product lines, increased sales could be leveraged by pharmacy benefit management companies contracting with employers and managed care organizations, and patients not yet taking medications could be identified. ${ }^{8}$

Whereas early disease management programs were directed mainly at enlarging target populations for drug therapy and increasing patient compliance with drug regimens, second-generation disease management programs have evolved in recent years toward a broader, population-based approach. A large commercial disease management industry has emerged that utilizes claims data to identify patients with selected chronic diseases. Commercial disease management vendors increasingly sell their programs for multiple diseases. Although participation in a disease management program has remained voluntary for patients, the trend in the disease management industry is to include all patients with selected chronic diseases unless they opt out of the program. ${ }^{9}$

Although some health plans develop their own disease management programs, many contract with private vendors to provide this function. A health plan or employer contracting for a disease management program will pay a per-member-per-month fee for a package of services, such as patient and clinician education, patient self-management, reminders, and alerts. The vendor agrees to specific performance guarantees, such as a certain percentage of cost savings and perhaps some health outcome measures. Fees may be at risk if performance goals are not met, but vendors are not obligated to pick up any added treatment costs and avoid clinical risk or responsibility for patient care. ${ }^{9}$

Two thirds of employers with 200 or more employees in 2005 had a disease management program in their job-based insurance plans; more than one half of all workers with employment-based insurance had a disease management program. The most common disease management program is for diabetes, closely followed by asthma, hypertension, and high-cholesterol programs. ${ }^{10}$ On the public sector side, more than 20 states are contracting for one or another kind of disease management programs for their Medicaid enrollees, ${ }^{11}$ and Medicare has already signed up 100,000 beneficiaries for disease management programs through 8 companies. ${ }^{12}$

\section{DOES DISEASE MANAGEMENT CUT COSTS AND IMPROVE QUALITY OF CARE?}

Evaluations of disease management programs are methodologically challenging, and most studies are limited by not having a control group or data on longer-term outcomes. The evidence to date is stronger for quality improvement in such programs than for cost savings, and many studies do not factor in the full costs of the disease management interventions themselves. To date, there are no studies that directly compare the outcomes of disease management programs integrated in primary care settings with outcomes of commercial programs. ${ }^{13}$

Some institutions that have introduced disease management programs based on a Chronic Care Model have achieved improved quality of care as a result, sometimes with modest short-term cost savings. One example is at Group Health Cooperative in Seattle, which adopted the Chronic Care Model in 1995. During the next 2 years overall costs went down by $11 \%$ for 15,000 diabetic patients (except for pharmacy costs, which went up by $16 \%$ ), and both specialty visits and hospital admissions were reduced by $25 \%{ }^{14}$; at the same time, quality improved as measured by sustained reductions of glycosylated hemoglobin $\left(\mathrm{HbA}_{1 \mathrm{c}}\right)$ levels. ${ }^{15}$ Another example is a Kaiser Permanente program in Northern California, where substantial quality improvement, but no cost savings, was achieved in a multidisciplinary disease management program for coronary artery disease, heart failure, diabetes, and asthma during a 6-year period from 1996 to $2002 .{ }^{16}$ In a later summary of 39 studies of outcomes from use of 
the Chronic Care Model, positive patient outcomes and/or care processes were found in 32 studies, with outcomes depending on how many of the 4 Chronic Care Model components were used (self-management, decision support, delivery system design, and clinical information system). ${ }^{17}$

Results are more ambiguous when one looks at the overall track record of all disease management programs, including those of the growing number of commercial vendors largely disconnected from primary care There are 3 recently published meta-analyses to draw upon. Tsai and colleagues ${ }^{18}$ examined 112 studies involving disease management programs based on the Chronic Care Model for asthma, congestive heart failure, diabetes, and depression. They found beneficial results across all these conditions, but noted mixed effects on quality of life (no benefit for asthma and diabetes), as well as publication bias for congestive heart failure and some asthma studies. Krause ${ }^{19}$ evaluated 67 studies involving more than 32,000 patients with diabetes, concluding that disease management programs are more effective when provided to severely ill enrollees and that even though a small to moderate positive impact was found, further study of comorbidity and costs incurred by enrollees is needed. A third meta-analysis was recently reported by Neumeyer-Gromen and colleagues for disease management programs for depression. ${ }^{20} \mathrm{On}$ the basis of 10 randomized controlled trials in the United States, they found significant improvements in quality of care at acceptable costs ranging from $\$ 9,051$ to $\$ 49,500$ per quality-adjusted life-year.

There are many smaller studies, especially those reporting experience by commercial disease management vendors, that show lower costs by such measures as hospitalizations and emergency department visits. One recent example is a 1-year report of telephonic nursing disease management for elderly patients with congestive heart failure, which resulted in a $10 \%$ cost saving after accounting for intervention costs. ${ }^{21}$

Several other recent outcome assessments cast doubt on disease management as a cost-containment strategy.

- A 2006 analysis of the number needed to decrease costs calculated that disease management programs will need to decrease hospital admissions by $10 \%$ to $30 \%$ to cover program fees alone. ${ }^{22}$

- The Congressional Budget Office stated in 2004 that "there is insufficient evidence to conclude that disease management programs can generally reduce overall health spending...."23

- A 2005 report by David Eddy and colleagues on the long-term effect of disease management on cost savings in diabetes concluded, "Even for the most optimistic picture-a 30-year horizon and assuming no turnover (patients stay with the same plan for 30 years) - the net effect on diabetes-related costs would

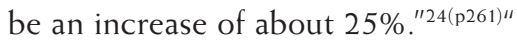

\section{DISEASE MANAGEMENT AND PRIMARY CARE}

The expanding disease management industry has emerged as a result of deficits in the quality of chronic disease care in many primary care settings across the country. Many factors account for this problem, including inadequate design of office practice for team management of chronic illness, underreimbursement of chronic disease care, lack of time, and lack of enabling information technology. ${ }^{25}$

Disease management programs based on the Chronic Care Model and integrated with primary care have shown promising results, likely to be lasting, for quality improvement.

Group Health Cooperative has taken its expertise and lessons on the road in an effort to train primary care teams in other parts of the country. With funding from a federal grant, disease management experts from Group Health have worked with more than 1,100 teams in more than 500 community clinics across the country to implement the Planned Care Model for management of diabetes, cardiovascular disease, depression, asthma, and obesity. After 13 months of training and collaboration, $82 \%$ of the pilot sites reported decreases in patients' average $\mathrm{HbA}_{1 \mathrm{c}}$ levels in diabetes from $8.4 \%$ to $7.6 \%$, and combined cardiac risk reduction scores showed an absolute risk reduction of $2.4 \% .{ }^{14}$

These excellent results require commitment, expertise, and adequate funding, together with an infrastructure that includes electronic medical records, disease registries, decision-support systems, patient reminders, and self-management materials. Those needs are not available in most primary care practices across the country, which are already grossly underreimbursed by private and public payers for the challenge of improving coordination and quality of chronic disease care.

Optimal management of chronic conditions is complex, particularly for patients with multiple chronic diseases. It is best done by well-trained primary care physicians working closely with other health professionals on a team basis. Management decisions are often difficult and must be individualized to each patient and family in a continuity of care relationship. How would it be possible, for example, for a nurse working with a commercial disease management vendor from a distant call center, without a relationship with the patient and primary care physician, to decide how to proceed in calibrating dosages of $\beta$-blockers, angiotensin-converting enzyme inhibitors, antidiabetes drugs, and antidepressants in a frail elderly patient on Medicare? 


\begin{tabular}{|c|c|c|}
\hline Characteristic & Integrated & Nonintegrated \\
\hline Ownership & $\begin{array}{l}\text { Not-for-profit managed } \\
\text { care organizations }\end{array}$ & $\begin{array}{l}\text { For-profit commer- } \\
\text { cial vendors }\end{array}$ \\
\hline Locus & Institutional-based & Outsourced \\
\hline $\begin{array}{l}\text { Linkage to primary } \\
\text { care physicians }\end{array}$ & Strong & Weak to none \\
\hline $\begin{array}{l}\text { Patient } \\
\text { participation }\end{array}$ & System-based for all & Optional \\
\hline Program horizon & Long-term & Short-term \\
\hline Motivation & Quality-oriented & Profit-oriented \\
\hline
\end{tabular}

More often than not, disease management today is being bought and sold between health plans, employers, and commercial vendors, without any real connection to the primary care system. Table 1 displays some major differences between not-for-profit institutional disease management programs and their commercial nonintegrated counterparts.

Disease management on a Chronic Care Model based in primary care is an important advance in the care of a growing part of the population. With training, reengineering of practice functions, and adequate funding, the elements of this model can be adapted to many primary care settings, as Group Health Cooperative has already shown in many community health centers across the country. With a strong link to primary care, quality of care can be improved, but cost savings cannot be assumed. Costs may actually increase as better quality of care is provided to patients previously undertreated for chronic conditions. There is no solid evidence yet that commercial for-profit disease management vendors will save money and improve care of chronic illness on a long-term basis. It is much more likely that the current enthusiasm among employers and insurers for outsourced disease management programs will end up as just one more policy failure, undermining primary care and delaying increasingly urgent health care reform.

To read or post commentaries in response to this article, see it online at http://www.annfammed.org/cgi/content/full/5/3/257.

Key words: Disease management; managed care programs; comprehensive health care; delivery of health care; primary health care

Submitted April 30, 2006; submitted, revised, September 14, 2006; accepted October 10, 2006.

Adapted from a presentation at the Seventeenth National Conference on Primary Health Care Access, April 8, 2006, Kauai, Hawaii.

\section{References}

1. Johns Hopkins University, Baltimore, Md. Partnership for Solutions. Available at: http://www.partnershipsforsolution.org. Accessed: 3 March 2006.
2. Hoffman C, Rice D, Sung HY. Persons with chronic conditions. Their prevalence and costs. JAMA. 1996;276(18):1473-1479.

3. Druss BG, Marcus SC, Olfson M, et al. Comparing the national economic burden of five chronic conditions. Health Aff (Millwood). 2001;20(6):233-241.

4. Institute of Medicine. Crossing the Quality Chasm: A New Health System for the Twenty-first Century. Washington, DC: National Academy Press; 2001.

5. Wagner EH, Austin BT, Von Korff M. Organizing care for patients with chronic illness. Milbank Q. 1996;74(4):511-544.

6. McCulloch D, Price M, Hindmarsh M, Wagner E. Improvement in diabetes care using an integrated population-based approach in a primary care setting. Dis Manag. 2000;3(2):75-82.

7. Welch WP, Bergsten C, Cutler C, Bocchino C, Smith RI. Disease management practices of health plans. Am J Manag Care. 2002;8(4):353-361.

8. Bodenheimer T. Disease management--promises and pitfalls. $N$ Engl J Med. 1999;340(15):1202-1205.

9. Sprague L. Disease management to population-based health: steps in the right direction? NHPF Issue Brief. 2003(791):1-16.

10. Gabel J, Claxton G, Gil I, et al. Health benefits in 2005: premium increases slow down, coverage continues to erode. The average cost of family coverage now exceeds the average yearly income of minimum-wage Americans. Health Aff (Millwood). 2005;24(5):1273-1280.

11. Wheatley B. Disease management: findings from leading state programs. State Coverage Initiat Issue Brief. 2002;3(3):1-6.

12. Landro J. Eliminating conflicts in medical treatment. Wall Street Journal. February 8, 2006: D:5.

13. Casalino LP. Disease management and the organization of physician practice. JAMA. 2005;293(4):485-488.

14. McCulloch D, Davis C, Austin B, Wagner E. Constructing a bridge across the quality chasm: a practical way to get healthier, happier patients, providers, and health care systems. Diabet Spect. 2004;17:92-96.

15. Wagner EH, Sandhu N, Newton KM, et al. Effect of improved glycemic control on health care costs and utilization. JAMA. 2001;285(2):182-189.

16. Fireman B, Bartlett J, Selby J. Can disease management reduce health care costs by improving quality? Health Aff. 2004;23(6):63-75.

17. Bodenheimer T, Wagner EH, Grumbach K. Improving primary care for patients with chronic illness: the chronic care model, Part 2. JAMA. 2002:288(15):1909-1914.

18. Tsai AC, Morton SC, Mangione CM, Keeler EB. A meta-analysis of interventions to improve care for chronic illnesses. Am J Manag Care. 2005;11(8):478-488.

19. Krause DS. Economic effectiveness of disease management programs: a meta-analysis. Dis Manag. 2005;8(2):114-134.

20. Neumeyer-Gromen A, Lampert T, Stark K, Kallischnigg G. Disease management programs for depression: a systematic review and meta-analysis of randomized controlled trials. Med Care. 2004;42(12):1211-1221.

21. Berg GD, Wadhwa S, Johnson AE. A matched-cohort study of health services utilization and financial outcomes for a heart failure disease-management program in elderly patients. J Am Geriatr Soc. 2004;52(10):1655-1661.

22. Linden AL. What will it take for disease management to demonstrate a return on investment? New perspectives on an old theme. Am J Manag Care. 2006;12(4):217-222.

23. Holtz-Eakin P. CBO Director, Testimony to Congress. 13 October 2004.

24. Eddy DM, Schlessinger L, Kahn R. Clinical outcomes and cost-effectiveness of strategies for managing people at high risk for diabetes. Ann Intern Med. 2005;143(4):251-264.

25. Casalino L, Gillies RR, Shortell SM, et al. External incentives, information technology, and organized processes to improve health care quality for patients with chronic diseases. JAMA. 2003;289(4):434-441. 